\title{
Studies on habit and habitat, external morphology, feeding capacity and prey preference of two striped spider, Telamonia dimidiata
}

\section{S.N. Chaubey}

\author{
Department of Zoology, \\ S.D.J.P.G. College, Chandeshwar, \\ AZAMGARH -276128 (U.P.) \\ Email: drsncchaubey@gmail.com
}

Received : 03.10.2019; Accepted : 08.11.2019

\begin{abstract}
Laboratory experiments were carried out to investigate habit and habitat, external morphology, preying capacity and prey preference of two striped spider, Telamonia dimidiata collected from different places of Uttar Pradesh India. It is found on trees, shrubs and paddy plants. Like other jumping spiders of family salticidae, these do not build webs and are sophisticated and active hunters. Telamonia dimidiata - recognisable by its distinctive two stripes on its back. This spider constructed a different web each night for three consecutive nights. "It is a cursorial hunter and does not use the web for hunting. Instead, it uses it as a resting ground to revisit, depending on whether it was disturbed or not," The female is light yellowish, with a very white cephalus and red rings surrounding the narrow black rings round the eyes where as male is very dark, with white markings, and red hairs around the eyes. Both the sexes feed actively on mosquitoes and moths and other insect pests acting as an efficient bio-control agent in gardens and crop fields.
\end{abstract}

Figures : 04

References : 13
Table : 01

KEY WORDS : Arachnida, Bio-control agent, Habit and habitat, Morphology, Preying capacity, Prey preference, Salticidae, Telamonia dimidiata.

\section{Introduction}

Spiders are found everywhere from blazing deserts to freezing climes, exhibiting extreme resilience, adaptability and unique survival mechanisms. It is no wonder that they endured calamities and are historically older than dinosaurs. Broadly, spiders are divided into two categories: Mygalomorphs or big spiders and Arnaeomorphs or small spiders (often only a few millimeters in length).

India is home to several unique species of spiders - some are known to science, while many others are yet to be discovered. According to an estimate, India is home to 59 families of spiders. Although spiders are often discussed based on their regional distribution - such as South Indian spiders and so on, they are not bound by these territories and can be found all over.

Despite their widespread presence, spiders are poorly studied. Very few known records of their natural history exist - not only of those found in the wilderness but of many commonly seen spiders found in homes, parks and backyards. "Most descriptions are based on preserved specimen. Field studies based on a living specimen collected and observed from the field enable easy identification.

Salticidae is a very large family contains the most colourful species of spiders. They are easily recognized by their eyes pattern. They have very good eyesight and very active. Each species in this family have different colourful patterns on their bodies. Jumping spiders are generally recognized by their eye pattern. All jumping spiders have four pairs of eyes with very large anterior median eyes. These are generally diurnal active hunters. Their well developed internal hydraulic system extends its limbs by altering the pressure of body fluid (haemolymph) within them. This enables the spiders to jump without having large muscular legs like a grasshopper. Most jumping spiders can jump several times the length of their body. When a jumping spider is moving from place to place and especially just before it jumps, it tethers a filament of silk (or dragline) to whatever it is standing on. Should it fall for one reason or another, it climbs back up the silk tether. 
TABLE-1: Feeding potential/ prey preference of Telamonia dimidiata.

\begin{tabular}{|c|c|c|c|c|c|c|}
\hline \multicolumn{7}{|c|}{ Type/Number of prey consumed/24h / Spider( Mean \pm S.D.) } \\
\hline S.No. & Lepidoptera & Diptera & Homoptera & Orthoptera & Coleoptera & Total \\
\hline 1 & 7 & 12 & 5 & 6 & 1 & 31 \\
\hline 2 & 9 & 11 & 4 & 4 & 0 & 28 \\
\hline 3 & 7 & 11 & 5 & 4 & 0 & 27 \\
\hline 4 & 8 & 13 & 6 & 5 & 0 & 32 \\
\hline 5 & 7 & 10 & 5 & 6 & 1 & 29 \\
\hline 6 & 7 & 11 & 5 & 5 & 1 & 29 \\
\hline 7 & 8 & 12 & 4 & 4 & 0 & 28 \\
\hline 8 & 8 & 12 & 6 & 4 & 0 & 30 \\
\hline 9 & 9 & 12 & 5 & 4 & 0 & 30 \\
\hline 10 & 7 & 11 & 5 & 5 & 1 & 29 \\
\hline Meant & $7.70 \pm 0.78$ & $11.50 \pm 0.81^{a}$ & $5.00 \pm 0.63^{a}$ & $04.70 \pm 0.78^{*}$ & $0.40 \pm 0.41^{a}$ & $29.30 \pm 1.42^{\mathrm{a}}$ \\
\hline
\end{tabular}

Significance level ${ }^{\mathrm{a}} 0.001$ and ${ }^{*}$ not significant when compared with adjacent means.

Jumping spiders are active hunters which means they do not rely on a web to catch their prey. Instead, these spiders stalk their prey. They use their superior eyesight to distinguish and track their intended meals, often for several inches. Then they pounce, giving the insect little to no time to react before succumbing to the spider's venom.

A detailed account of spiders of Jabalpur, Madhya Pradesh has been provided ${ }^{6}$, description of arachnid fauna of Nallamalai region, Eastern Ghats Andhra Pradesh (India) and a taxonomic studies of some spiders from Mangrove and Semi-Mangrove areas of Sunderban, studies on some spiders from Eastern Coastal region of India and various aspects of spiders of Sunderbans, West Bengal (India) respectively has been made ${ }^{7,11}$. Zygiella melanocrania $^{3}$ and Plexippus paykuli (Audeuin) ${ }^{5}$ have been reported from U.P. India. Recently Opisthoncus spider has been described from U.P. ${ }^{4}$.

Most of the findings are concerned with habit and habitat, external morphology, prey preference and feeding capacity of spiders.

From the review of literature, it appears that role of spiders as bio-control agents in agriculture, poultry as well as in controlling house-hold insects is being studied in various parts of the world, but unfortunately, proper investigation, regarding role of these efficient biocontrol agents in India is scanty.

In the present investigation, therefore, it has been to find out habit and habitat, external morphology, preying capacity and prey preference of two striped spider, Telamonia dimidiata collected from various places of U.P. (India).

\section{Materials and Method}

Collection of spiders: Individuals of Opisthoncus species were collected from walls, crop fields, orchards, ornamental and wild plants.

Mehods of collection: Following techniques were used for collection of spiders:

Jarring: The foliage spider fauna was collected by jerking the plants on a cloth sheet from which the specimens were transferred alive into plastic containers having pores in their corks for aeration and brought to the laboratory for studies.

Direct hand picking: Collection of most web building spiders was made by direct hand picking with the help of test tubes.

Inverted Umbrella: In this method an inverted 


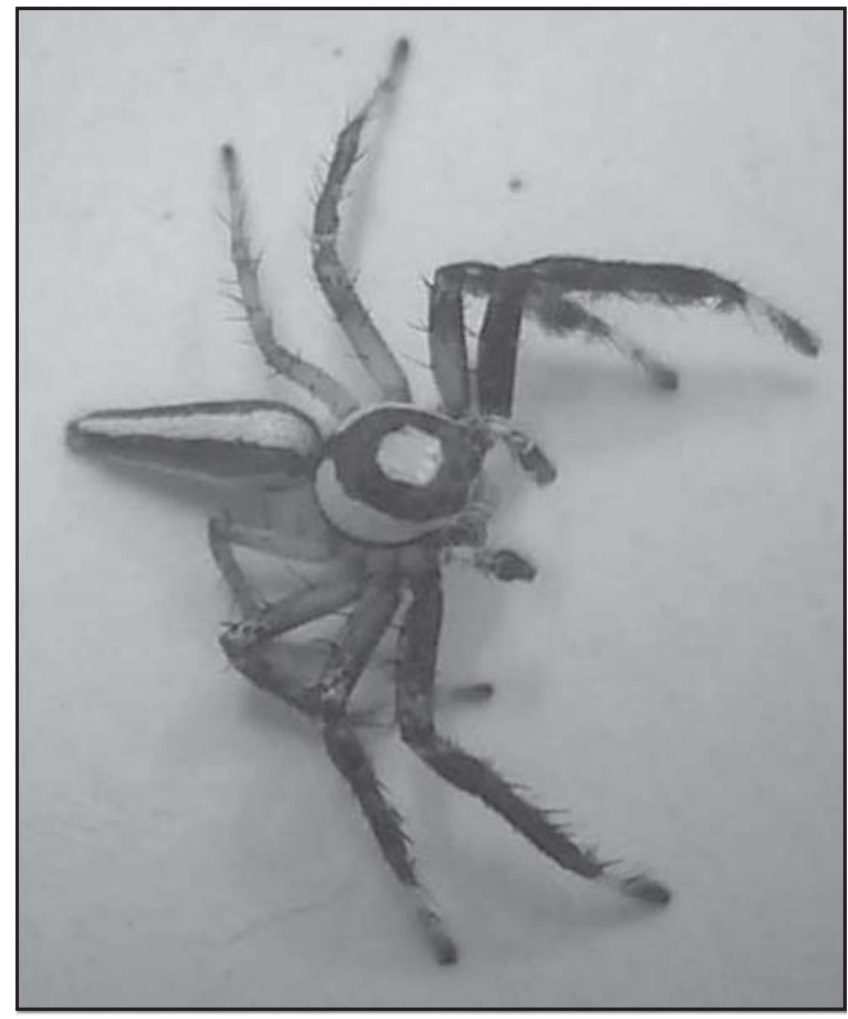

Fig. 01

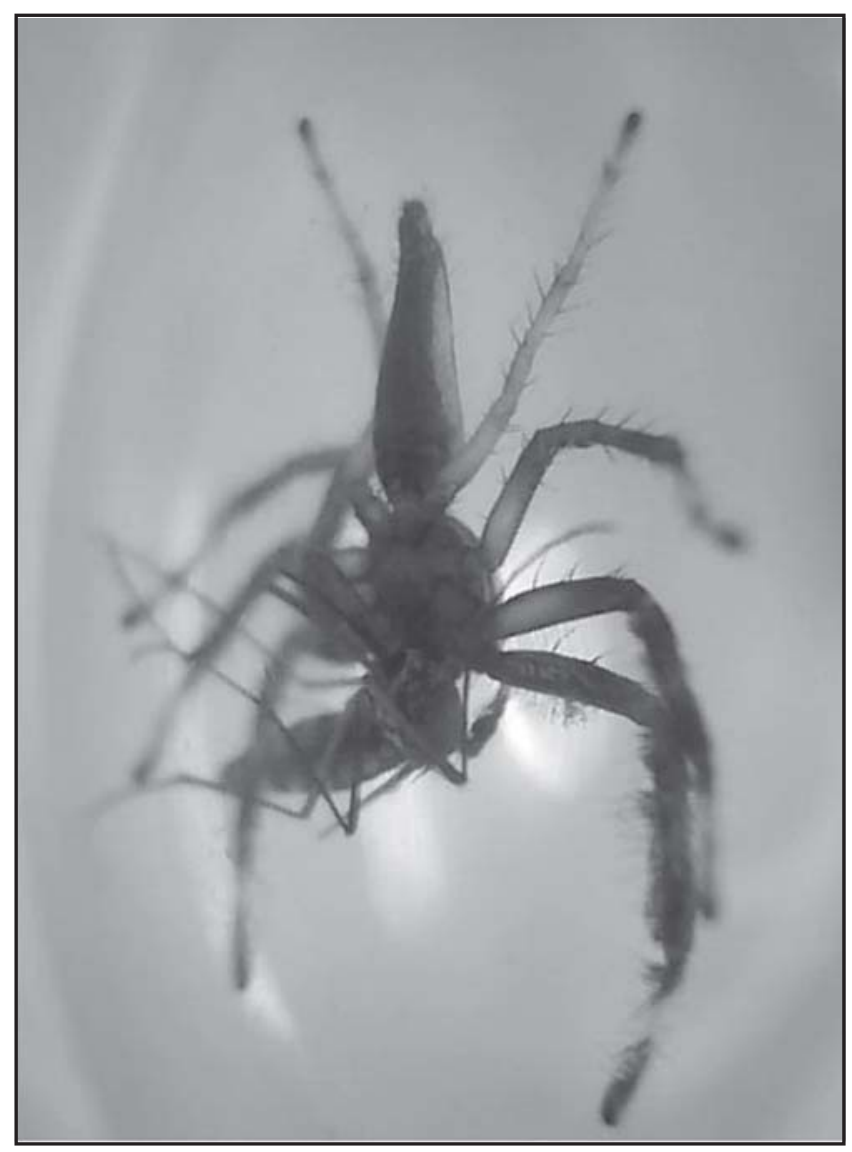

Fig. 03

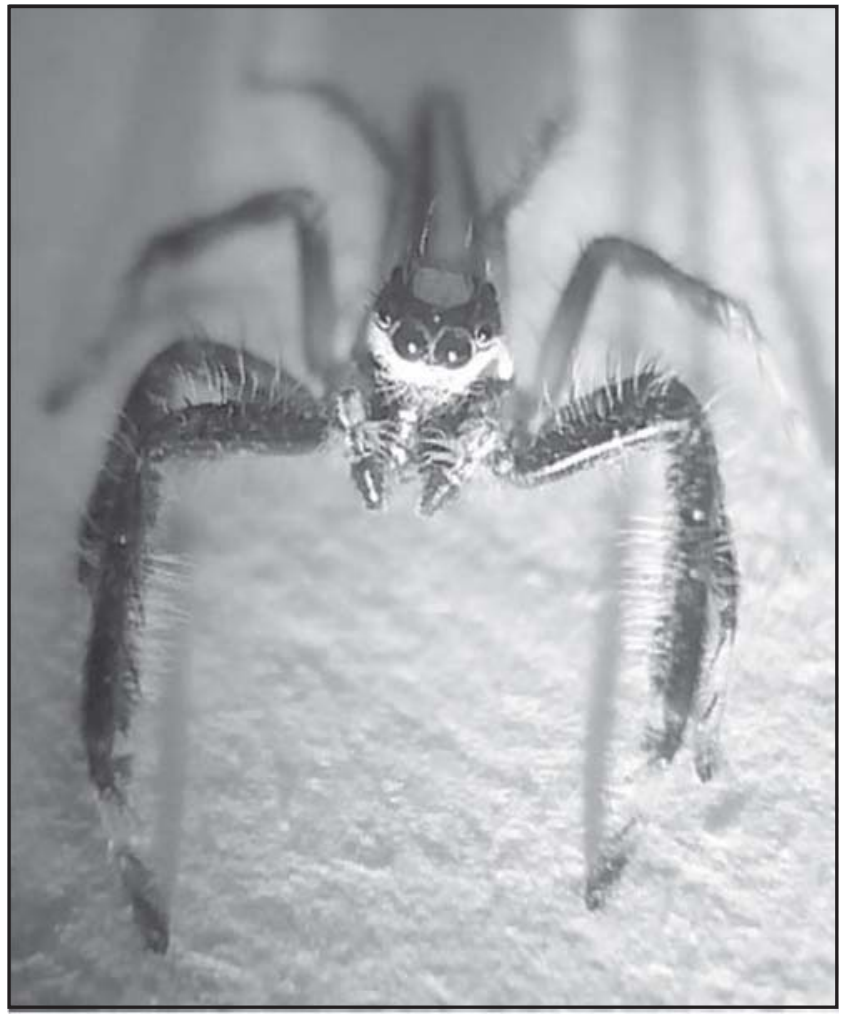

Fig. 02

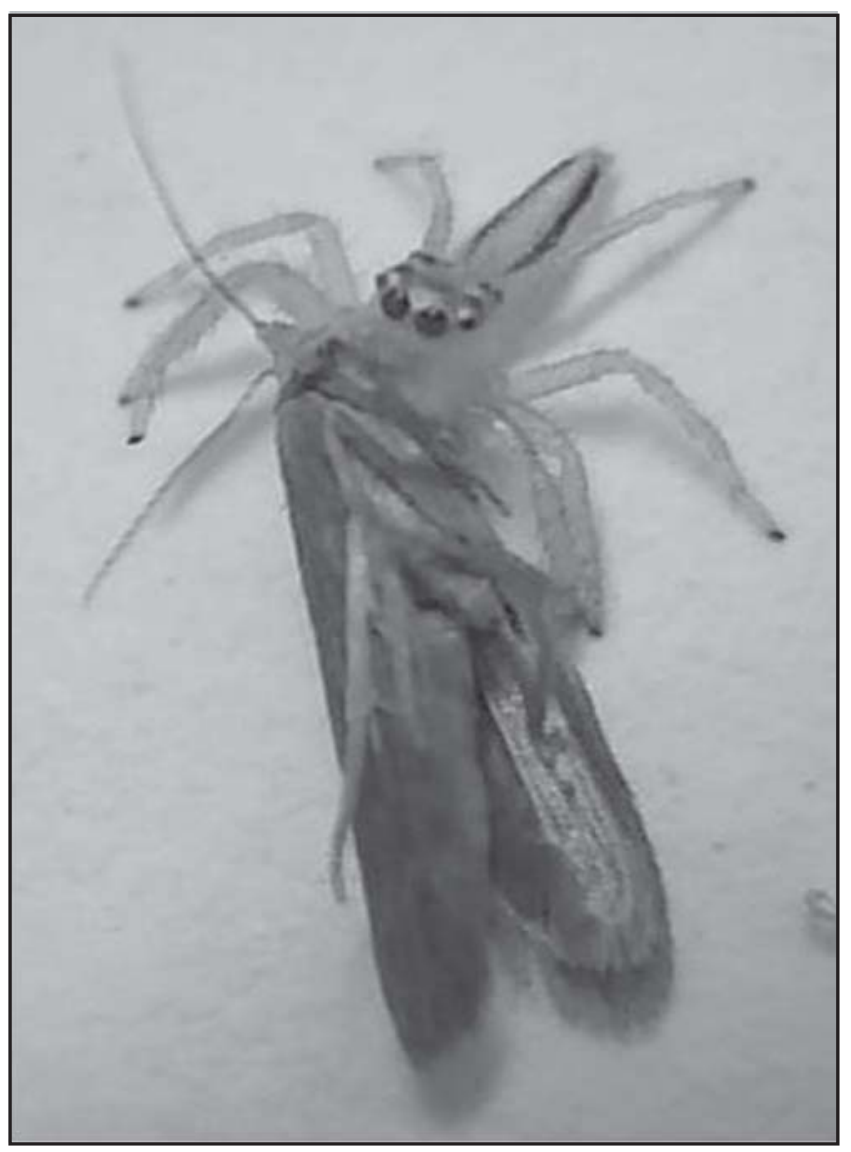

Fig. 04

Telamonia dimidiata (Male): Fig.01: Dorsal view, Fig.02: Front view, Fig.03: Male feeding on mosquito, Fig.04: Female feeding on adult moth. 
umbrella was placed below flowering shoots and bushes and when the tree or branch was thoroughly shaken, spiders along with insects fallen to the inverted umbrella. After removing leaves, spiders were transferred into collecting tubes.

Preservation: Before the spiders were permanently preserved they were arranged properly. For this, collected specimens were transferred into petridish containing Isopropyl alcohol. It was kept covered undisturbed for about 2 or 3 hours in order to allow the relaxation of body muscles. The body parts like legs, abdomen and palps were then arranged in a life like manner with the help of forceps and brush. Spiders were then kept in alcohol in a closed pair of petridish overnight before transferring to tubes for permanent preservation. The glass vial containing preserved specimens were stoppered by a rubber cork to prevent evaporation of alcohol. Alternatively, glass vials were plugged by cotton and group of these tubes were then placed in large bottle containing alcohol. This was the method used for preserving most specimens. Each collecting tube enclosed a label indicating the collection data. Collection data include the name of the collector, place of collection, date of collection and habitat of collection.

Photography: Live photographs of all important spiders were taken with the help of Web Cam of 12 mega pixel attached to computer. For taking alive photographs, the spiders were anesthetized with mild doses of chloroform in specimen tubes. Generally, major diagnostic features such as dorsal view, ventral view, ocular area and side view were taken for the study. Natural photographs of spiders were taken while they were feeding on insects.

Identification: It was done on the basis of morphometric characters of various body parts. The help was mainly taken from the keys and catalogues ${ }^{1,10}$ and photographs available on internet and other relevant literature.

Study of prey choice: To study the prey choice of the collected spiders, adult house flies, rice moth, mosquitoes and their larvae and small insects were supplied to spiders which were kept under rearing chambers.

Each rearing chamber $(9.5 \mathrm{~cm}$ height, $6.0 \mathrm{~cm}$ length and width) was consisted of transparent plastic containers. The lid of each container was provided with small holes for aeration. Since, spiders are highly cannibalistic, individual spiders were kept in separate chambers.

To study prey choice, spiders were kept starved for $24 \mathrm{~h}$, then each spider was supplied with larvae and adults of moths, house flies and mosquitoes along with small insects collected from houses and surroundings (five individuals of each kind of prey in each rearing chamber). After $12 \mathrm{~h}$ number of fed and live prey individuals were counted to find out preference of their prey. Attempts were also made to take live photographs while spiders were preying.

Study of preying potential: For this purpose spiders were kept starved for $24 \mathrm{~h}$ and then each spider was supplied with various kinds of insect pests like adult moths, house flies and mosquitoes (ten individuals of each type) separately in their individual rearing chambers. After $12 \mathrm{~h}$, dead, fed and live prey were counted.

Statistical analyses: Each experiment was repeated ten times and student's t-test was applied for comparison between two sample means.

\section{Results and Discussion}

\section{Classification:}

Phylum: Arthropoda, Class: Arachnida, Order:Araneae Family: Salticideae, Genus: Telamonia, Species: dimidiata.

Habit and habitat: The two-striped jumper, or Telamonia dimidiata, is a jumping spider found in paddy crop fields, vegetable gardens, shrubs and foliage in wooded environments. It is also found in various Asian tropical rain forests, in foliage in wooded environments. They appear in Singapore (New Record), Indonesia, Pakistan, India, Bhutan.

Description: The male is very dark, with white markings and red hairs around the eyes. Legs I and II of the males are armed with thick brushes of bristles (Figs. $1 \& 2$ ). Females are larger than male individuals. The female is light yellowish, with a very white cephalus and red rings surrounding the narrow black rings round the eyes. Two longitudinal bright red stripes are present on the opisthosoma (Fig. 04). Similar description has also been given ${ }^{8,9}$.

Economic importance: Both the sexes feed actively on mosquitoes and moths (Fig. 3 \& 4) and other insect pests (Table-01) acting as an efficient bio-control agent in gardens and crop fields.

Telamonia dimidiata (Simon) (Two striped spider) is a jumping spider found in various Asian tropical rain forests, in foliage in wooded environments. They appear in Singapore (New Record), Indonesia, Pakistan, India, Bhutan.

Remark: This species is being reported here for the first time from U.P. (India). Both the sexes fed actively on mosquitoes, moths (Figs. 3 \& 4) and other insect pests acting as an efficient bio-control agent in gardens and crop fields as also reported for other spider species $2-5,12,13$ 


\section{References}

1. Biswas BK, Biswas K. Fauna of Sikkim (Araneae: Spiders), State fauna Series. 2003; 3: 357-500.

2. Carter PE, Rypstra AL. Top-down effects in soybean agroecosystems: spider density affects herbivore damage. Oikos. 1995; 72: 433-439.

3. Chaubey SN. Studies on habit and habitat, external morphology, feeding capacity and prey preference of worbweaving spider, Zygeilla melanocrania. Flora and Fauna. 2017; 23 (2): 439-444.

4. Chaubey SN. Studies on habit and habitat, external morphology, feeding capacity and prey preference of garden jumping spider, Opisthoncus species. Indian J. Sc. Res. (In Press). 2019.

5. Chaubey SN, Yadav PR. Studies on habit and habitat, external morphology, feeding capacity and prey preference of zebra jumper spider Plexippus paykuli (Audeuin). J. Exp. Zool. India. 2017; 20 (2) : 901-905.

6. Gajbe P. Spiders of Jabalpur, Madhya Pradesh (Arachnida: Araneae). Zool. Surv. India, Kolkata. 2004; pp. 1-154.

7. Majumder SC. Pictorial Handbook on Spiders of Sunderbans West Bengal: (Published by the Director, Zool. Surv. India, Kolkata). 2007; pp 1-137.

8. Mishra RS. Unpublished Ph.D. Thesis entitled "Studies on the role of predatory insects in biological control of rice pests of middle east (U.P.)" V.B.S. Purvanchal University Jaunpur. 2012.

9. Murphy F, Murphy J. An Introduction to the Spiders of South East Asia. Malaysian Nature Society, Kuala Lumpur. 2000.

10. Platnick NI. The world spider catalog, version 8.0. American Museum of NaturalHistory. 2007; Online at http:// research.amnh.org/entomology/spiders/catalog/index.html.

11. Rao TK, Bastawade DB, Maqsood Javed SM, Siva Rama Krishna I. Arachnid fauna of Nallamalai Region, Eastern Ghats, Andhra Pradesh, India, Rec. Zool. Surv. India, (Published by the Director, Zool. Surv. India, Kolkata). 2005; 239: 1-42.

12. Riechert SE, Bishop L. Prey control by an assemblage of generalist predators - spiders in garden test systems. Ecology. 1990; 71: 1441-1450

13. Symondson WOC, Sunderland KD, Greenstone $\mathrm{MH}$. Can generalist predators be effective biocontrol agents? Annual Review of Entomology. 2002; 47: 561-594. 